\title{
Spectroscopic Studies of Methimazole Reactivity toward the Aquapentacyanoferrate (II) Ion in Aqueous Solutions
}

\author{
D. Cvijanović, V. Damjanović, I. Picek, and B. Foretić \\ Department of Chemistry and Biochemistry, School of Medicine, University of Zagreb, \\ 10000 Zagreb, Croatia
}

Correspondence should be addressed to D. Cvijanović, danijela.cvijanovic@mef.hr

Copyright (C) 2012 D. Cvijanović et al. This is an open access article distributed under the Creative Commons Attribution License, which permits unrestricted use, distribution, and reproduction in any medium, provided the original work is properly cited.

Abstract. Methimazole (2-mercapto-1-methylimidazole, MMI) and its pentacyanoferrate (II) complex have been characterized by means of UV/Vis, Raman, and NMR spectroscopy. The reaction of MMI with aquapentacyanoferrate (II), $\left[\mathrm{Fe}(\mathrm{CN})_{5}\left(\mathrm{H}_{2} \mathrm{O}\right)\right]^{3-}$, in buffered aqueous solutions yielded the $\left[\mathrm{Fe}(\mathrm{CN})_{5}(\mathrm{MMI})\right]^{3-}$ complex. It was found that only thione tautomer of MMI coordinates to the iron (II). The exceptionally stabile and inert complex was produced.

Keywords: 2-mercapto-1-methylimidazole, pentacyanoferrate (II) complexes, spectroscopy

\section{Introduction}

Methimazole (2-mercapto-1-methylimidazole, MMI) is known to have several chemotherapeutic applications, particularly in the treatment of thyroid disorders. The reactions and coordination ability of $S, N$-containing heterocyclic ligands such as MMI have been of considerable interest both from the structural point of view and pharmacological importance [1]. MMI exists in thiol and thione tautomeric forms (Figure 1) and consequently acts as ambidentate ligand. This study has been undertaken to investigate the coordination mode of MMI to the pentacyanoferrate (II) moiety, $\left[\mathrm{Fe}(\mathrm{CN})_{5}\right]^{3-}$, as a good selective probe for binding one specific group of ambidentate ligands to iron (II).

\section{Experimental}

\subsection{Materials and Instruments}

Methimazole was a reagent-grade Aldrich product that was used as purchased. $\mathrm{Na}_{3}\left[\mathrm{Fe}(\mathrm{CN})_{5}\right.$ $\left.\left(\mathrm{NH}_{3}\right)\right] \cdot 3 \mathrm{H}_{2} \mathrm{O}$ (Sigma-Aldrich) was used after recrystallization. Solutions of $\left[\mathrm{Fe}(\mathrm{CN})_{5}\left(\mathrm{H}_{2} \mathrm{O}\right)\right]^{3-}$ were freshly prepared by aquation of $\left[\mathrm{Fe}(\mathrm{CN})_{5}\left(\mathrm{NH}_{3}\right)\right]^{3-}$ at room temperature and kept in the dark to minimize 


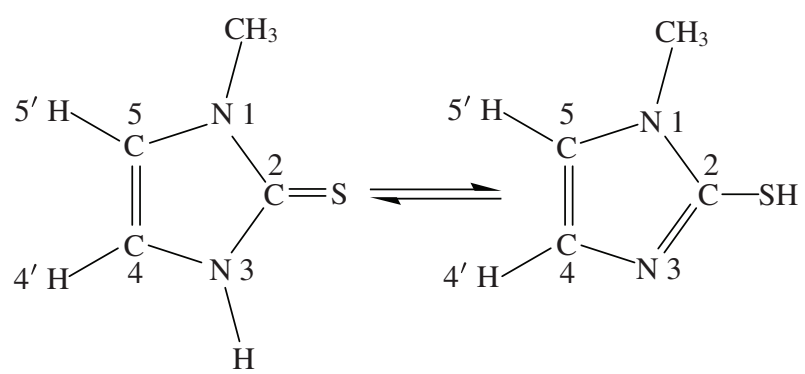

Figure 1: The tautomeric forms of MMI.

thermal and photolytic decomposition. The constant $\mathrm{pH}$ values of the aqueous solutions were maintained by using Britton-Robinson buffers [2]. A constant ionic strength of $0.1 \mathrm{M}$ was adjusted by the addition of sodium chloride. Acetonitrile, ethanol, and chloroform were solvents of spectrophotometric reagent grade (Sigma-Aldrich; $\geq 99.5 \%$ ). Sodium hydroxide and hydrogen peroxide solution were reagent grade. Deionized water was used throughout.

The $\mathrm{pH}$ measurements were performed at $25^{\circ} \mathrm{C}$ on a Mettler Toledo $\mathrm{pH}$ meter with an InLab 413 electrode accurate to $\pm 0.01 \mathrm{pH}$ units.

\subsubsection{NMR Studies}

The ${ }^{1} \mathrm{H},{ }^{13} \mathrm{C}$, and ${ }^{15} \mathrm{~N}$ NMR spectra, plus a ${ }^{1} \mathrm{H}_{-}{ }^{15} \mathrm{~N}$ (HMBC) spectrum, were recorded in DMSO- $d_{6}$ on a Bruker Avance 600 spectrometer operating at $600.1\left({ }^{1} \mathrm{H}\right.$ and $\left.{ }^{1} \mathrm{H}_{-}{ }^{15} \mathrm{~N}\right), 150.9\left({ }^{13} \mathrm{C}\right)$, and $60.8\left({ }^{15} \mathrm{~N}\right) \mathrm{MHz}$. The ${ }^{1} \mathrm{H}$ and ${ }^{13} \mathrm{C}$ chemical shifts were relative to TMS as internal standard, while the ${ }^{15} \mathrm{~N}$ chemical shifts were determined with respect to the external standard $\mathrm{NH}_{4} \mathrm{NO}_{3} .{ }^{1} \mathrm{H} \mathrm{NMR}(\delta / \mathrm{ppm}): 3.45\left(\mathrm{~s}, \mathrm{NCH}_{3}\right) ; 7.04$ $\left(\mathrm{d}, J=2.23 \mathrm{~Hz}, \mathrm{H} 4^{\prime}\right) ; 6.87\left(\mathrm{~d}, J=2.34 \mathrm{~Hz}, \mathrm{H} 5^{\prime}\right) ; 12.03(\mathrm{br}, \mathrm{NH}) .{ }^{13} \mathrm{C} \mathrm{NMR}(\delta / \mathrm{ppm}): 33.47\left(\mathrm{NCH}_{3}\right)$; 113.95 (C4); 119.35 (C5); 161.12 (C=S). ${ }^{15} \mathrm{~N}$ NMR ( $\left.\delta / \mathrm{ppm}\right): 167.08 .{ }^{1} \mathrm{H}-{ }^{15} \mathrm{~N}$ HMBC $(\delta / \mathrm{ppm}): 170.12$ $\left(\mathrm{NCH}_{3}\right) ; 167.2(\mathrm{~N} 3)$; spin-spin coupling of the isolated proton and ${ }^{15} \mathrm{~N} 3$ nucleus was not observed. The comparison of the ${ }^{1} \mathrm{H},{ }^{13} \mathrm{C}$, and ${ }^{15} \mathrm{~N}$ chemical shifts with the reported values $[3,4]$ confirmed that the used MMI ligand was present in DMSO solely as thione tautomer.

\subsubsection{UV/Vis Electronic Spectroscopy: Equilibrium and Kinetic Studies}

All measurements were carried out on a Varian Cary Bio 100 spectrophotometer with thermostated cell holders in the range from 220 to $900 \mathrm{~nm}$. The electronic spectra of MMI were acquired in buffered aqueous solutions ( $\mathrm{pH} 2.0-11.5), 0.2 \mathrm{M} \mathrm{NaOH}\left(\lambda_{\max }=245 \mathrm{~nm} ; \varepsilon=15200 \mathrm{M}^{-1} \mathrm{~cm}^{-1}\right)$, pure water $\left(\lambda_{\max }=251 \mathrm{~nm} ; \varepsilon=17400 \mathrm{M}^{-1} \mathrm{~cm}^{-1}\right)$, and ethanol $\left(\lambda_{\max }=259 \mathrm{~nm} ; \varepsilon=21600 \mathrm{M}^{-1} \mathrm{~cm}^{-1}\right)$ as polar protic solvents, acetonitrile $\left(\lambda_{\max }=264 \mathrm{~nm} ; \varepsilon=16100 \mathrm{M}^{-1} \mathrm{~cm}^{-1}\right)$ as a polar aprotic solvent, and chloroform $\left(\lambda_{\max }=270 \mathrm{~nm} ; \varepsilon=15400 \mathrm{M}^{-1} \mathrm{~cm}^{-1}\right)$ as a nonpolar solvent.

The composition and stability of the produced complex were investigated at $25^{\circ} \mathrm{C}, I=0.1 \mathrm{M}$ and $\mathrm{pH}=5.1$. The analytical concentration of $\left[\mathrm{Fe}(\mathrm{CN})_{5}\left(\mathrm{H}_{2} \mathrm{O}\right)\right]^{3-}$ in all reaction mixtures was held constant, $c=4 \cdot 10^{-4} \mathrm{M}$, while the concentration of MMI was varied. Absorbances collected at $\lambda_{\max }$ 
were analyzed. The stability constant was evaluated by nonlinear regression of the experimental data to the hyperbolic curve valid for the spectrophotometric mole ratio method [5] as follows:

$$
\begin{aligned}
A_{\lambda_{\max }}=\frac{1}{2} A_{\lim } \cdot(1+z & +\frac{1}{\beta_{11} \cdot c\left(\left[\mathrm{Fe}(\mathrm{CN})_{5}\left(\mathrm{H}_{2} \mathrm{O}\right)\right]^{3-}\right)} \\
& -\sqrt{\left.\left(1+z+\frac{1}{\beta_{11} \cdot c\left(\left[\mathrm{Fe}(\mathrm{CN})_{5}\left(\mathrm{H}_{2} \mathrm{O}\right)\right]^{3-}\right)}\right)^{2}-4 z\right)}
\end{aligned}
$$

The mole ratio of ligand to metal analytical concentrations is defined by parameter $z$, and $A_{\text {lim }}$ is the theoretical absorbance corresponding to the quantitative reaction.

The dissociation kinetics was performed under pseudo-first-order conditions by following the absorbance decrease at $580 \mathrm{~nm}$ after addition of different excesses of DMSO as a scavenger ligand. The first-order dissociation rate constant, $k_{\mathrm{d}}$, was obtained from the plots of $\ln \left(A_{\mathrm{t}}\right)$ against time which were linear for at least three half-lives and is expressed as the average of six replicate experiments.

\subsubsection{Raman Solution Studies}

Raman spectra of the sample solution, placed in liquid sphere, were recorded at ambient temperature using FT-Raman module of Perkin-Elmer GX spectrometer with a resolution of $4 \mathrm{~cm}^{-1}$ and InGaAs detector. The excitation line of Nd:YAG laser operating at the power of $1000 \mathrm{~mW}$ was at $1064 \mathrm{~nm}$. Spectral range was from 100 to $3500 \mathrm{~cm}^{-1}$.

The recorded spectra of MMI $(w \approx 5 \%)$ in chloroform and buffered aqueous media $(\mathrm{pH}=5)$ were compared with the recently reported thione-thiol vibrational assignments for solid state and in aqueous media [6]. The similar position and the shape of the bands found for MMI in chloroform and as solid indicated the predomination of thione tautomer $[6,7]$. The shifts toward higher frequencies and drop in intensities were found in aqueous media, and the bands characteristic for the thione form found at 1583 , 1464 , and $527 \mathrm{~cm}^{-1}$ have shown its reduced amount.

In order to prevent dimerization of $\left[\mathrm{Fe}(\mathrm{CN})_{5}\left(\mathrm{H}_{2} \mathrm{O}\right)\right]^{3-}$ and H-bonding association of MMI, the $10^{-3} \mathrm{M}$ buffered reaction mixture was prepared and kept in the dark for $2 \mathrm{~h}$. The volume of solution of the complex, quantitatively produced, was reduced by evaporation $(w \approx 4 \%)$ prior to the Raman spectrum recording. Two strong and sharp cyanide stretching frequencies at 2060 and $2096 \mathrm{~cm}^{-1}$ were observed, consistent with the group-theoretical prediction of approximately $\mathrm{C}_{4 \mathrm{v}}$ symmetry of octahedral pentacyanoferrate (II) complexes [8].

\section{Results and Discussion}

The electronic spectrum of MMI in water, just like in buffered aqueous solutions up to $\mathrm{pH} 10.5(\mathrm{pH}$ 2.0-10.5), exhibited wide, intensive absorption band centered at $c a .250 \mathrm{~nm}\left(\varepsilon=17000 \mathrm{M}^{-1} \mathrm{~cm}^{-1}\right)$. Based on the similarity of conjugation electronic systems present in thiol and thione forms of MMI, 
such spectral appearance is in accordance with the existence of both tautomeric forms. The recent study of the respective population of the MMI's thione-thiol tautomeric forms at various $\mathrm{pH}$ performed by

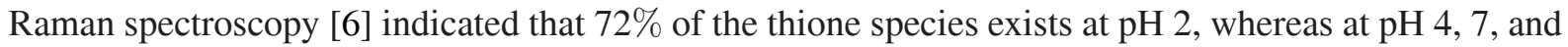
9 the percentage of thione species decreases up to maximally $65 \%$. In more alkaline media, the slight blue shift of absorption maximum was observed which culminated (by $5 \mathrm{~nm}$ ) in $0.2 \mathrm{M} \mathrm{NaOH}$ solution and was attributed to the ionization of MMI. This is in agreement with its known $\mathrm{p} K_{\mathrm{a}}$ value of 11.6 [6]. Regarding the solvent influence on the absorption properties of MMI, one characteristic absorption band was found in chloroform, acetonitrile, and ethanol (see Section 2.1.2.). Although the stabilization of thione or thiol tautomeric forms of various mercaptothiazoles appeared to be independent of solvent [9], the absolute predomination (99-100\%) of MMI's thione form in polar aprotic DMSO and nonpolar chloroform was established by NMR studies [4]. Thus, the blue shift of MMI's absorption maximum observed from non-polar to protic polar solvents is presumably caused by the increase in thiol content. This is in agreement with the solution Raman spectra obtained in chloroform and buffered aqueous media.

The aquapentacyanoferrate (II) reacts with MMI by forming a blue-colored complex whose absorption maximum's energy is independent of $\mathrm{pH}$ and the molar ratio of the reactants in the reaction mixture. Maximal absorbances are obtained in the acidic $\mathrm{pH}$. At equal initial concentrations of the reactants $\left(c=4 \cdot 10^{-4} \mathrm{M}\right), I=0.1 \mathrm{M}, \mathrm{pH}=5.12 \pm 0.01$, and $25^{\circ} \mathrm{C}$, the equilibrium is reached in about 30 minutes. The blue color of the complex slowly fades upon addition of hydrogen peroxide confirming that the iron involved in coordination is in the bivalent oxidation state. Under the specified reaction conditions, more than $50 \%$ of MMI molecules exist in solution as the thione tautomer. Thione ligands are known to form stable complexes with pentacyanoferrate (II) and (III) species, displaying strong metal-to-ligand or ligand-to-metal charge-transfer bands in the visible region, respectively [10].

The UV/Vis electronic spectrum of the complex exhibits several absorptions. The band appearing around $225 \mathrm{~nm}\left(\varepsilon=9700 \mathrm{M}^{-1} \mathrm{~cm}^{-1}\right)$ is consistent with a charge transfer between $\mathrm{CN}^{-}$and $\mathrm{Fe}^{2+}$ $[8,10]$, while the intensive band at $253 \mathrm{~nm}\left(\varepsilon=10000 \mathrm{M}^{-1} \mathrm{~cm}^{-1}\right)$ and the shoulder at $283 \mathrm{~nm}$ $\left(\varepsilon=6800 \mathrm{M}^{-1} \mathrm{~cm}^{-1}\right)$ are due to internal $\pi \rightarrow \pi^{*}$ transitions within the coordinated ligand. The low intensity maximum at $420 \mathrm{~nm}\left(\varepsilon=330 \mathrm{M}^{-1} \mathrm{~cm}^{-1}\right)$ is interpreted as $\mathrm{d}-\mathrm{d}^{1} \mathrm{~A}_{1} \rightarrow{ }^{1} \mathrm{E}_{(1)}$ transition [8], whereas the somewhat asymmetric band at $580 \mathrm{~nm}\left(\varepsilon=1140 \mathrm{M}^{-1} \mathrm{~cm}^{-1}\right)$ is characteristic of the complex attributed to the $\mathrm{d}_{\pi}\left(\mathrm{Fe}^{\mathrm{II}}\right) \rightarrow \mathrm{p}_{\pi}^{*}(\mathrm{MMI})$ charge transfer presumably involving the iron (II) thione chromophore. The spectrophotometric mole ratio method revealed the formation of a complex of $1: 1$ stoichiometry and an equilibrium constant of $\log \left(\beta_{11} / \mathrm{M}^{-1}\right)=6.94$. Consequently, the substitution of water in $\left[\mathrm{Fe}(\mathrm{CN})_{5}\left(\mathrm{H}_{2} \mathrm{O}\right)\right]^{3-}$ with $\mathrm{MMI}$ and the related equilibrium constant is presented by the following equation:

$$
\left[\mathrm{Fe}(\mathrm{CN})_{5}\left(\mathrm{H}_{2} \mathrm{O}\right)\right]^{3-}+\mathrm{MMI} \underset{k_{\mathrm{d}}}{\stackrel{k_{\mathrm{f}}}{\rightleftarrows}}\left[\mathrm{Fe}(\mathrm{CN})_{5}(\mathrm{MMI})\right]^{3-}+\mathrm{H}_{2} \mathrm{O} \quad \beta_{11}=\frac{\left[\left[\mathrm{Fe}(\mathrm{CN})_{5}(\mathrm{MMI})\right]^{3-}\right]}{\left[\left[\mathrm{Fe}(\mathrm{CN})_{5}\left(\mathrm{H}_{2} \mathrm{O}\right)\right]^{3-}\right] \cdot[\mathrm{MMI}]}
$$

In accordance with a limiting $\mathrm{S}_{\mathrm{N}} 1$ (D) mechanism, the rates of formation of $\left[\mathrm{Fe}(\mathrm{CN})_{5}(\mathrm{~L})\right]^{3-}$ complexes are found to be completely independent of the nature of the entering ligand. Assuming a similar formation rate constant for neutral ligands at the same ionic strength, an average value of the 
second-order formation constant $k_{\mathrm{f}}\left(25^{\circ} \mathrm{C}\right)=294 \mathrm{M}^{-1} \mathrm{~s}^{-1}$ deduced from the published results [10] is taken as the rate constant for the formation of the $\left[\mathrm{Fe}(\mathrm{CN})_{5}(\mathrm{MMI})\right]^{3-}$ complex. The pseudo-firstorder constant for the dissociation reaction of $\left[\mathrm{Fe}(\mathrm{CN})_{5}(\mathrm{MMI})\right]^{3-}$ was found to be independent of the concentration of the scavenger DMSO $(0.01-0.5 \mathrm{M})$ and was identified as $k_{\mathrm{d}}$, equal to $9 \cdot 10^{-5} \mathrm{~s}^{-1}$. The equilibrium constant for the $\left[\mathrm{Fe}(\mathrm{CN})_{5}(\mathrm{MMI})\right]^{3-}$ complex deduced from kinetic parameters $\left(\beta_{11}=\right.$ $\left.k_{\mathrm{f}} / k_{\mathrm{d}}\right)$ was equal to $\log \left(\beta_{11} / \mathrm{M}^{-1}\right)=6.51$ at $25^{\circ} \mathrm{C}$ and was in very good agreement with the value obtained by the mole ratio method.

The obtained values of $k_{\mathrm{d}}$ and $\beta_{11}$ indicated that $\left[\mathrm{Fe}(\mathrm{CN})_{5}(\mathrm{MMI})\right]^{3-}$ is inert and stabile complex which along with the observed relatively high cyanide stretching Raman frequencies implicates the substantial degree of $\pi$-back donation. Although imidazole and histidine coordinate to the $\left[\mathrm{Fe}(\mathrm{CN})_{5}\right]^{3-}$ moiety, producing relatively inert and stabile complexes [10], the $\mathrm{N}$ atom of the imidazole ring in both tautomeric forms of MMI is not available for coordination because of protonation or the steric hindrance from the vicinal thiol group. The obtained kinetic and thermodynamic properties are comparable with those found for the pentacyanoferrate (II) complexes with thione donor groups [10] and strongly support the coordination of MMI via the thione group. Furthermore, the coordination of thiol tautomer through a poor $\pi$-acceptor -SH group would lead to the formation of labile pentacyanoferrate (II) complex, as was the case with cysteine, penicillamine, 2-mercaptoethylamine, and glutathione [11].

\section{Authors' Contribution}

D. Cvijanović and V. Damjanović contributed equally to this work.

\section{References}

[1] P. D. Akrivos, "Recent studies in the coordination chemistry of heterocyclic thiones and thionates," Coordination Chemistry Reviews, vol. 213, no. 1, pp. 181-210, 2001.

[2] D. D. Perrin and B. Dempsey, Buffers for pH and Metal Ion Control, Chapman and Hall, London, UK, 1974.

[3] E. Buncel, A. R. Norris, S. E. Taylor, and W. J. Racz, "Metal ion-biomolecule interactions. IV. Methylmercury (II) complexes of 1-methylimidazoline-2-thione (methimazole), a potentially useful protective agent in organomercurial intoxication," Canadian Journal of Chemistry, vol. 60, no. 24, pp. 3033-3038, 1982.

[4] R. S. Balestrero, D. M. Forkey, and J. G. Russell, "15N NMR: Iminothiol-thioamide tautomerism of 2-mercaptobenzazoles and 1-methyl-2-mercaptoimidazole," Magnetic Resonance in Chemistry, vol. 24, no. 8, pp. 651-655, 1986.

[5] M. Boccio, A. Sayago, and A. G. Asuero, "A bilogarithmic method for the spectrophotometric evaluation of stability constants of 1:1 weak complexes from mole ratio data," International Journal of Pharmaceutics, vol. 318, no. 1-2, pp. 70-77, 2006.

[6] N. Biswas, S. Thomas, A. Sarkar, T. Mukherjee, and A. S. Kapoor, "Adsorption of methimazole on silver nanoparticles: FTIR, Raman, and surface-enhanced Raman scattering study aided by density functional theory," Journal of Physical Chemistry C, vol. 113, no. 17, pp. 7091-7100, 2009.

[7] H. T. Flakus, A. Miros, and P. G. Jones, "Polarization IR spectra of model crystals containing cyclic N-H. . .S bonded dimers: 2-Mercaptothiazoline and 2-mercapto-1-methylimidazole," Spectrochimica Acta. Part A, vol. 58, no. 2, pp. 225-237, 2002. 
[8] D. H. Macartney, "Properties and reactions of substituted pentacyanoferrate (II) complexes," Reviews in Inorganic Chemistry, vol. 9, no. 2-3, pp. 101-152, 1988.

[9] E. S. Stern and C. J. Timmons, Gillam and Stern's Introduction to Electronic Absorption Spectroscopy in Organic Chemistry, Edward Arnold, London, UK, 1st edition, 1970.

[10] F. S. Nunes, L. D. S. Bonifácio, K. Araki, and H. E. Toma, "Interaction of 2- and 4-mercaptopyridine with pentacyanoferrates and gold nanoparticles," Inorganic Chemistry, vol. 45, no. 1, pp. 94-101, 2006.

[11] D. H. MacArtney and A. McAuley, "Kinetics of the formation and dissociation of pentacyanoferrate (II) complexes of cysteine, penicillamine, glutathione, and 2-mercaptoethylamine," Journal of the Chemical Society, Dalton Transactions, no. 9, pp. 1780-1787, 1981. 


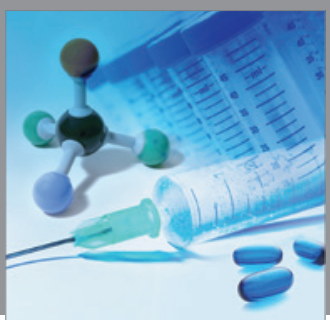

International Journal of

Medicinal Chemistry

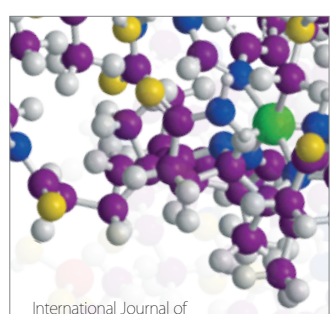

Carbohydrate Chemistry

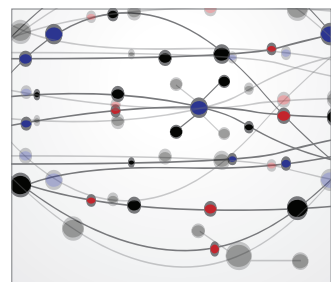

The Scientific World Journal
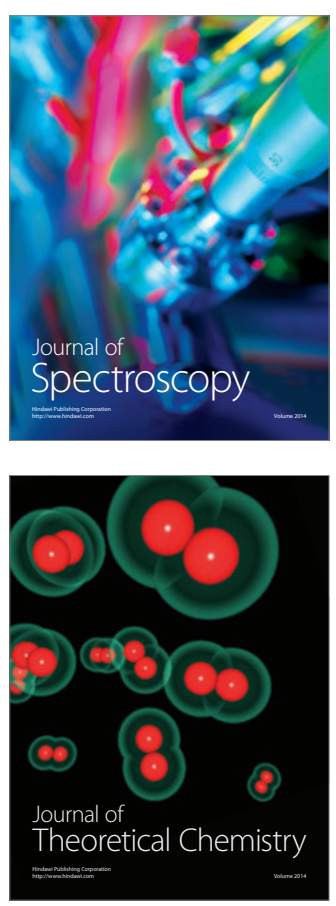
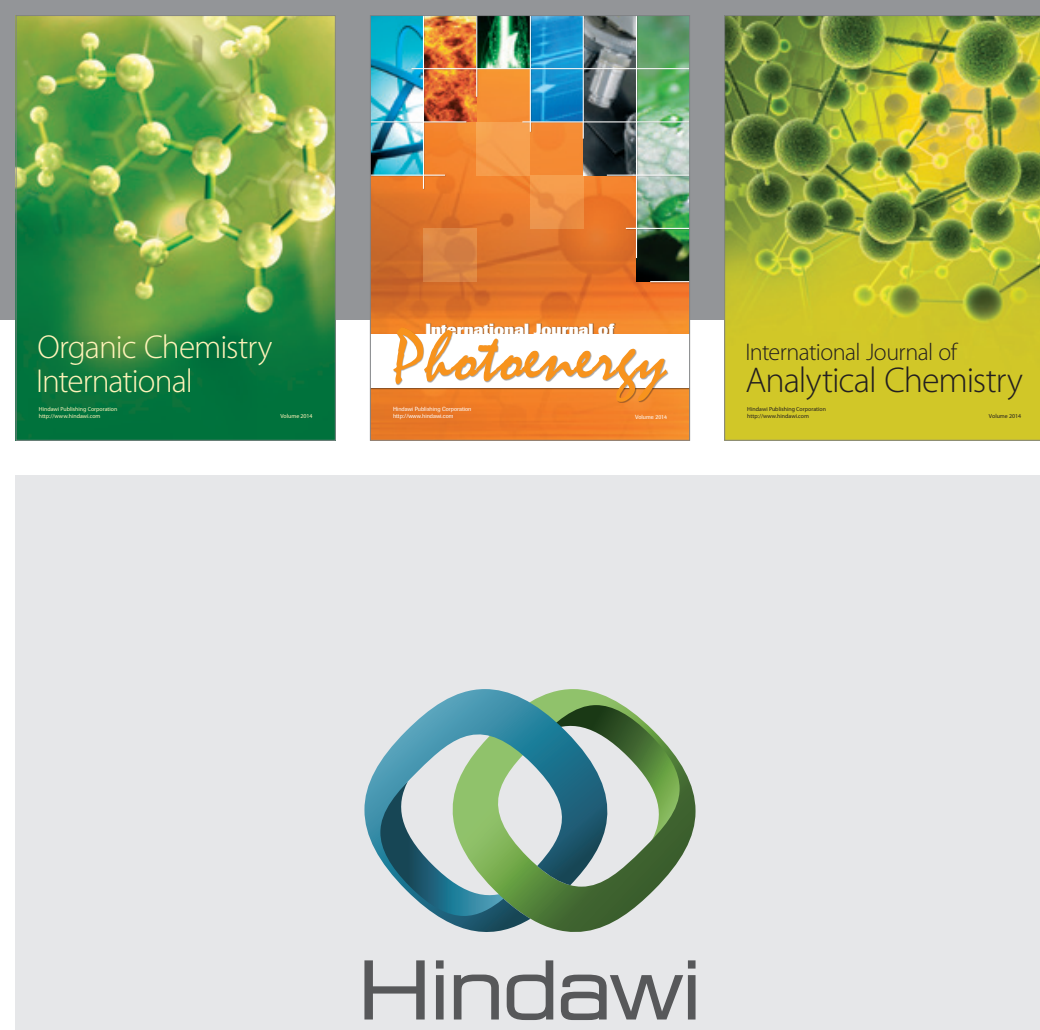

Submit your manuscripts at

http://www.hindawi.com
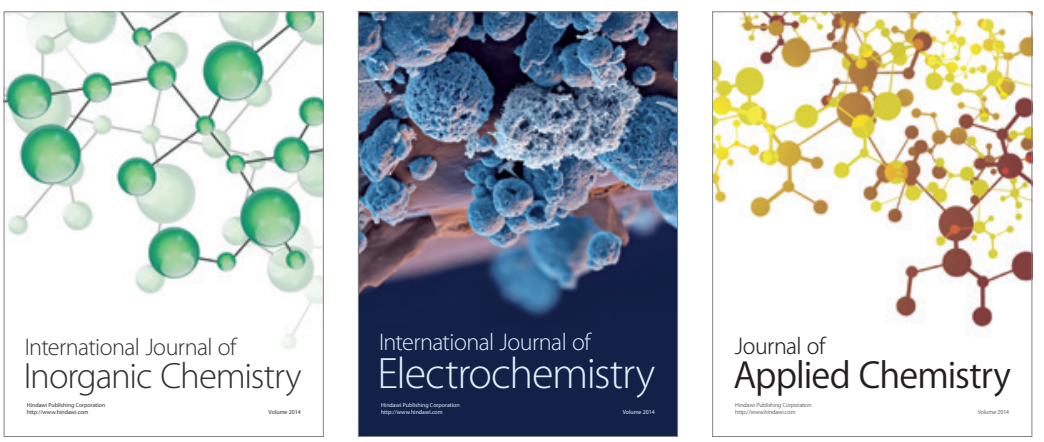

Journal of

Applied Chemistry
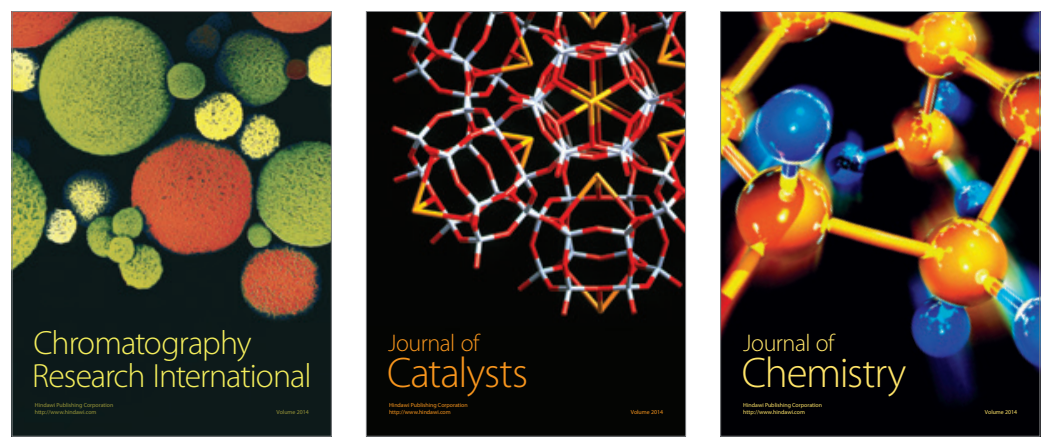
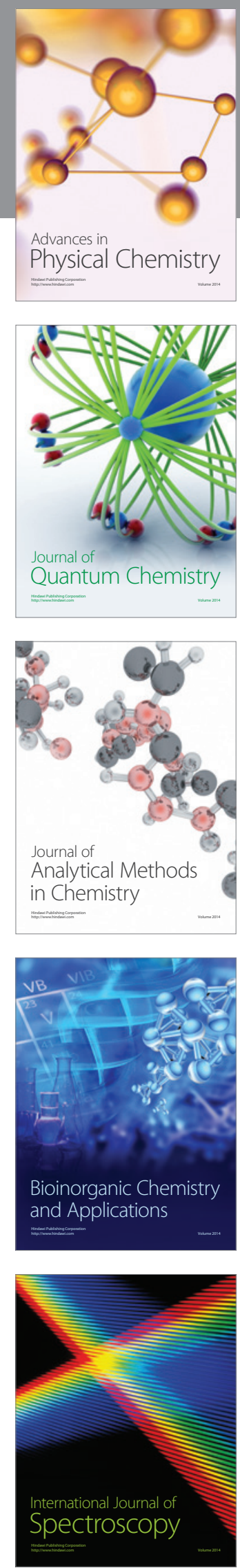